\title{
Strategic Human Resource Development Practices -A study at National Thermal Power Corporation Limited (NTPC), Ramagundam, Telangana and Simhadri Plant, Vishakhapatnam, Andhra Pradesh, India.
}

${ }^{1}$ Dr. Pavan Patel, ${ }^{2}$ Dr. Vikram K. Joshi

${ }^{1}$ Professor, Siva Sivani Institute of Management, NH-7, Kompally, Secunderabad-500100, Telangana.

${ }^{2}$ Assistant Professor - DMT, Shri Ramdeobaba College of Engineering and Management, Ramdeo Tekdi, Gittikhadan, Katol Road, Nagpur-440013, Maharashtra.

Email: pavanpatel@ssim.ac.in,vikramkjoshi@gmail.com

Received: $20^{\text {th }}$ September 2018, Accepted: $11^{\text {th }}$ October 2018, Published: $31^{\text {st }}$ October 2018

\begin{abstract}
Human resource development practices are very important for development of the organisation. According to 'Best employers Survey in India' conducted by Business standard, NTPC is standing in top 10 position consecutively for many years due to the HRD practices at NTPC. Human resource development practices at NTPC Limited are mutually benefitted to employees as well as organisation. Hence, the present study intends to understand the HRD practices of NTPC and evaluate the employee's perception towards HRD practices in terms of motivation, career development and contribution towards work performance. For the study, survey of 120 employees is conducted at NTPC Limited(NTPC) Ramagundam, Telangana and Simhadri Plant, Vishakhapatnam. The study concludes that NTPC is proactive in implementing the best practices in HRD to keep employees motivated to fulfil the goals of the organization.
\end{abstract}

Keywords

Human Resource Development, Training \& Development, Career Development and Organisational Development

\section{Introduction}

In the era of cut-throat competition and global economic changes, the leading organizations are forced to undertake massive reforms to cope up with the business challenges by updating, upgrading and tapping new opportunities. The organizations are shifting the focus from traditional HR practices to modern strategic HRD practices which are more value-creating and responsive to the volatile business environment. There exists a high degree of correlation between the success of any organisation and the strategic human resource development practices adopted by an organization. According to Eneh \& Awara (2016), increased emphasis must be given on SHRD practices such as training, recruitment, reward, planning, selection, promotion, etc., that will create value for the organization. The strategic HRD practices ensure organizational effectiveness for the foreseeable future and increases the moral of the managers and workers to keep themselves ready for new developments. It is the strategic HRD practices leads to create strategies, create training \& development opportunities taking into consideration the company's vision, statement of mission and goals of the organization to motivate the employees and organization to achieve their business goals.

NTPC is the largest energy giant of India established in the year 1975 to facilitate power development in India. It has created its present by establishing its dominance in the power sector by integrating the value chain of the business of power generation. It has marked its presence from fossil fuels and ventured into electricity generation from hydro to nuclear and to renewable energy sources to reduce its carbon footprint. It has also diversified into various fields which includes power trading, consultancy, rural electrification, coal mining, ash utilization, training of power professionals, etc.

NTPC has earned the reputation not only in power generation, but also is recognized as the best place to work as it is guided by the principle "People before Plant Load Factor (PLF)". To add one more feather in cap, it has been ranked as $6^{\text {th }}$ Best Company to work in India amongst the PSU during the year 2014 by Great Places to Work Institute in collaboration with ET (Economic Times).

Thus, looking at the progress and the performance NTPC has achieved, one can easily interpret that the HRD functions of NTPC are highly encouraging and aligned towards the progress of the employee and organization. Also, it is noticed that NTPC is now no more an organization conducting the traditional training and development activities, but increasing its focus on strategic HRD practices replacing traditional training and development practices. According to 'Best employers Survey in India' conducted by Business standard, NTPC is continuously standing in top 10 position consecutively for many years. This survey clearly highlighted that one of the significant reason for NTPC standing in top of the list is because of the HRD practices at NTPC. Hence, the study of such kind will give better understanding and insights into the various SHRD practices with 
special emphasis on training and development activities performed by NTPC and its relative contribution in achieving the goals of the organization.

Objectives of the Study:

1. To understand the existing HRD practices of NTPC.

2. To evaluate the employee's perceptions towards training \& development programmes of NTPC and its usefulness to the organization in terms of improving the work performance and accomplishing the career objectives of the employees.

\section{Material and Methods}

The study is descriptive and empirical study conducted at NTPC, Ramagundam, Telangana and Simhadri Plant, Vishakhapatnam, Andhra Pradesh, India during the period 2014-17. A structured questionnaire was administered to 120 employees of the organization belonging to two different plants. The responses were captured using a Likert's 5-point scale ( 1 - Strongly disagree to 5 - Strongly agree). The 120 employees selected were the participants in the various training and development programmes conducted at two different plants during the period 2014-17. The survey was conducted at three levels: Executive level, Supervisory Level and Workmen Level of the employees.

Through the survey primary data was collected and suitably interpreted and analyzed. Also, the secondary data was collected from the official website of NTPC for various information like profile of the company, vision, mission statements and core values of the company. The company has officially collected feedback from the participants was also used for the purpose of study.

\section{Sample Profile of the Respondents:}

The age-wise and level-wise distribution of sample respondents is presented as below:

\begin{tabular}{|l|c|c|l|c|c|}
\hline Age (years) & No. of Employees & Percentage & Level & No. of Employees & Percentage \\
\hline Below 30 & 36 & $30 \%$ & Executive & 13 & $10.8 \%$ \\
\hline $30-45$ & 60 & $50 \%$ & Supervisory & 48 & $40 \%$ \\
\hline Above 45 & 24 & $20 \%$ & Workman & 59 & $49.2 \%$ \\
\hline Total & 120 & 100 & Total & 120 & 100 \\
\hline
\end{tabular}

Table 1: Age-wise and Level-wise Distribution

From the table 1, it can be observed that most of the employees who are undergoing training fall in the age category of 30-45 years and below 30 years (combined $80 \%$ ). This shows that most of the respondents belong to relatively younger age. Similarly, the highest number of respondents undergone training belongs to workman level $(49.2 \%)$ followed by supervisory level $(40 \%)$. Thus, the company seems to be more focussed towards enhancements of skills of workmen followed by supervisory level. The intentions of the company are very loud and clear in terms of their focus while imparting skills and training.

\section{Results and Discussion}

\section{Present Human Resource Development Practices in the Company}

The practices observed with regard to strategic human resource development as given as below:

\section{- Conduct of Training and Development Programs (Seven Man Days of the Training)}

In NTPC the training for the employees of all levels is mandatory for seven days in a year; these days are called as seven man days of the training. All the training programs are aligned with the vision, mission, goals statements and the strategies of the organization. After completion of each training program, the participants are required to submit the feedback forms designed by the company which are mapped with various objectives set for the training and the accomplishment of the objective of the training. This feedback is evaluated by the HRD team to identify the gaps in the training programs.

Also, the company has its own method of training need analysis. This is done by the company three months well in advance before the training calendar preparation which commences from April ${ }^{\text {st }}$ to March $31^{\text {st }}$ of every year.

\section{- Sponsored Training Programs in Premier Institutes}

In NTPC the senior executives are encouraged to attended sponsored training programs in premier institutes like Administrative Staff College of India (ASCI), Hyderabad Management Development Institute (MDI) Gurgaon and all Indian Institute of Management institutes (IIM) etc. as per the need of the employee. 
- Employee Development Centre (EDC)

In NTPC, Employee development centre (EDC) directly facilitating the employees in realistic career development through conducting innovative competitions among various plant of NTPC Ltd. These competitions are encouraged by top management by investing considerable time and resources for the development of employees.

It also organizes the induction and orientation programs for employees that are well accepted by employees as it helped them in building realistic career planning. The various training programs that are designed are communicated well in advance to the participants.

Perceptions of the Employees towards Training and Development Programs

The survey was conducted to know the effectiveness and use of the training and development programs at NTPC. The results are presented as below:

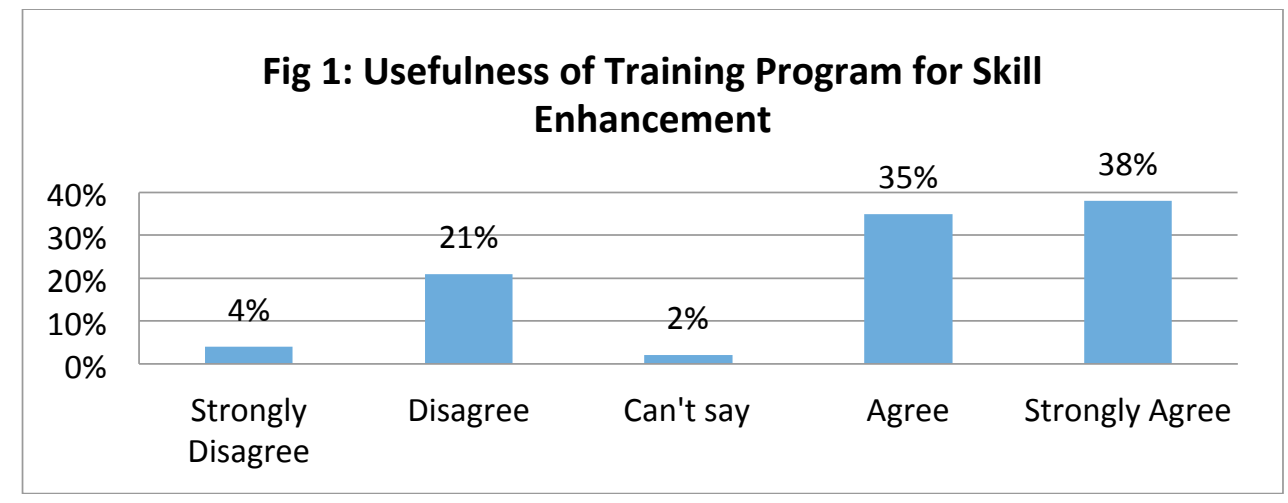

From the Fig 1, it can be observed that $73 \%$ of employees expressed their agreement with regard to the useful of the training program for their work in the organisation, $21 \%$ employees felt differently that transferring the skill, knowledge and abilities from training programs are not completely transferred to the work place, $4 \%$ of employees completely disagreed that these are not so useful for their jobs. $2 \%$ employees expressed their neutral view. Thus, it can be inferred that the training programs are need based and adds value by enhancing necessary skills amongst the employees.

Fig 2 below shows the results of the perception of the employees towards availability of opportunities to acquire advanced training for necessary job related skill enhancements.

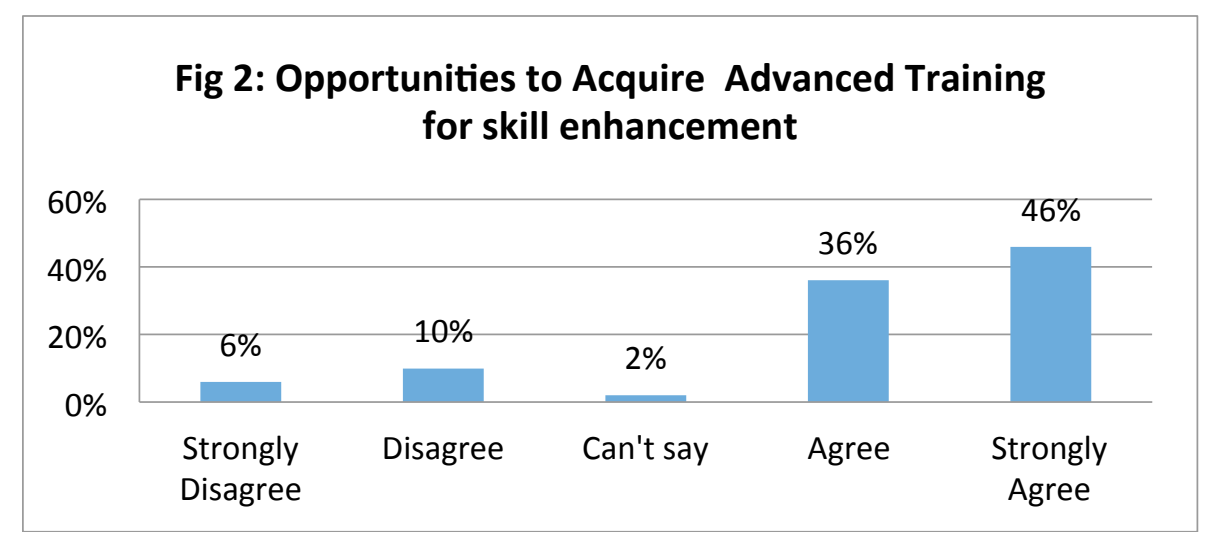

It is observed that $82 \%$ employees expressed their agreement with regard to availability of opportunities of skills upgradation as and when felt by any employee in the organization, rather such practices are encouraged by the organization amongst the employees, as expressed by the employees.

Fig 3 below shows the survey results on employee's perception at three levels with regard to existence of gaps in the training programs. 


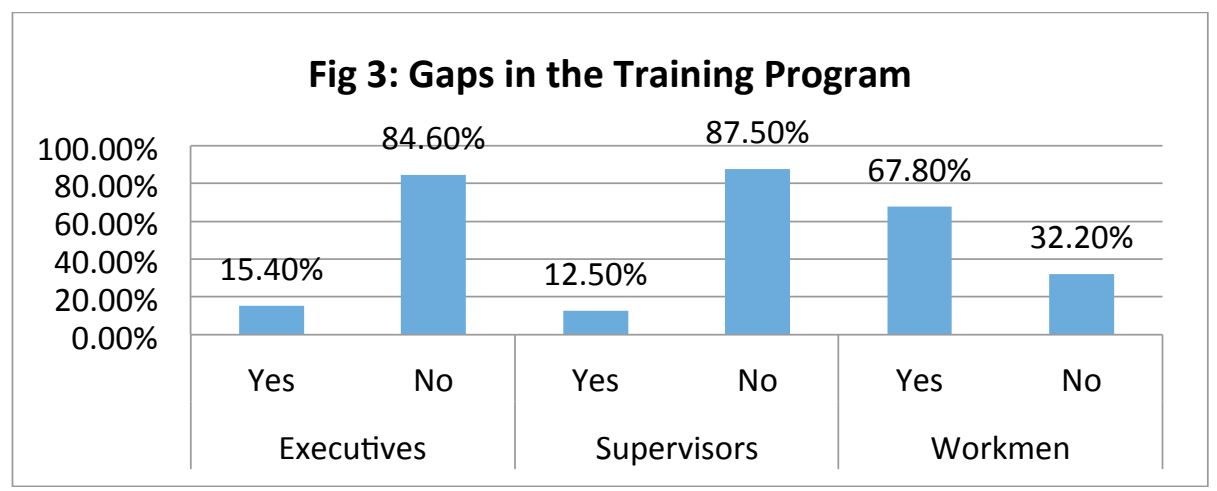

It can be seen that $67.80 \%$ workmen feel that the gaps are existing in the training programs, but at other two levels, the gap doesn't exists. Thus, it can be inferred that employees at executives and supervisors level are very much convinced that the company is doing clear cut need based assessment for formulating and designing the training programs. At third level (workmen level), the company needs to focus more.

The training programs organized by the company comprise of technical and non-technical components. Fig 4 below shows the perception of employees towards the training programs with respect to increase in motivational level.

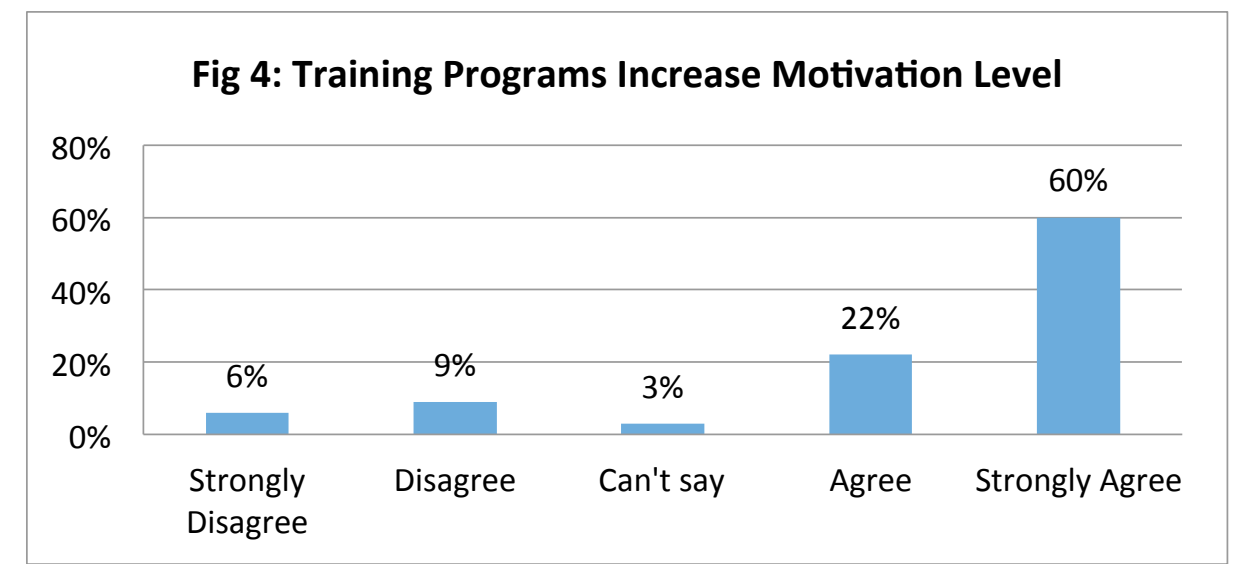

It can be seen that $60 \%$ employees strongly feel that the training programs are highly motivating, $22 \%$ expressed their agreement and opined that the trainings were helped them to learn how to motivate their departmental colleagues in the plant. Remaining employees felt that it is a routine process in the organisation most of them were workmen. Amongst the $82 \%$ employees who expressed their agreement, $89 \%$ employees substantiated that the various methods incorporated in training which includes experimental, action orientation techniques like management games, simulation, case studies related to internal issues of NTPC and from different industry practices enriched them and motivated them to use it in their jobs.

The respondents were asked about the contribution of training program towards enhancing individual sustainability in changing business environment. The results are presented in Fig 5 below:

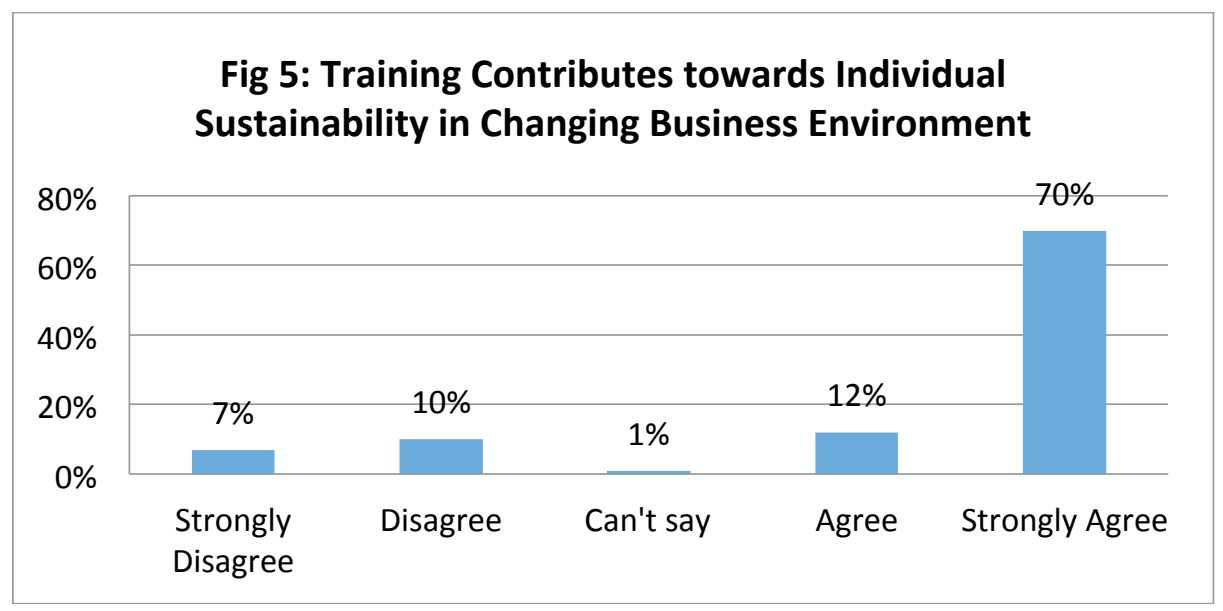


It can be observed that $70 \%$ of employees expressed strong agreement and opined that the training impart necessary knowledge and skills for individual sustainability in changing business environment. $17 \%$ employees feel that the training does not impart necessary knowledge and skills most of whom are the workmen.

The respondents were asked about the training sharpened their decision-making skills. The results are presented as below in Fig 6.

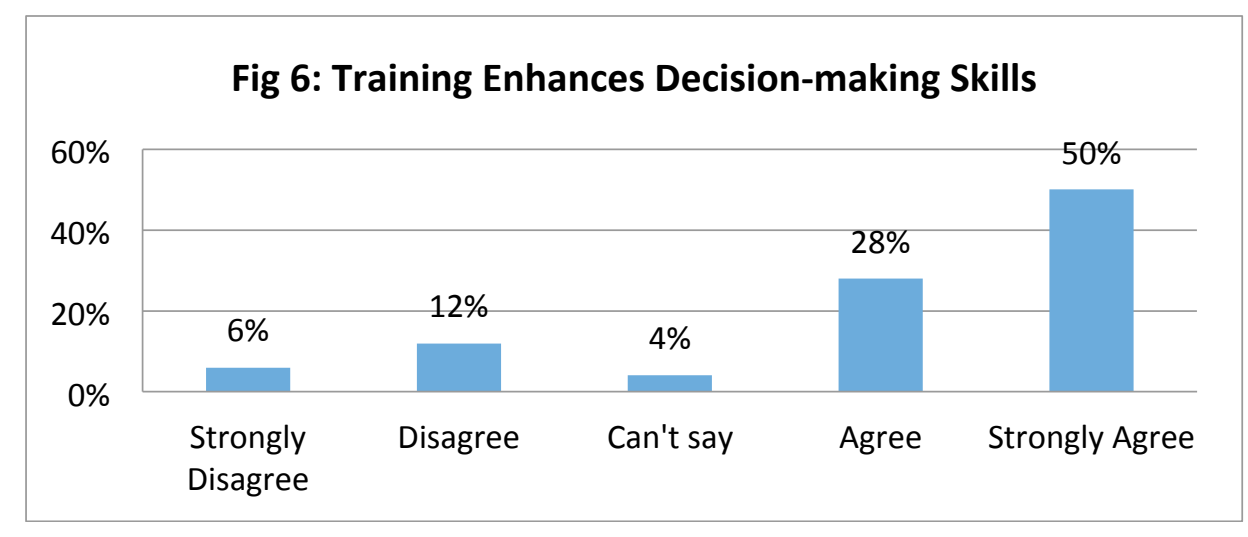

It can be observed that $50 \%$ employees expressed strong agreement whereas $28 \%$ only agree. $18 \%$ employees feel that the training doesn't help them in increasing their decision-making skills. This shows the success of the training programs designed by the organization. The company conducts various training programs some of which are technology upgradation training programs and rest are non-technological training programs. $80 \%$ employees at all levels agreed that these programs are really useful and helped them in contributing towards the business of the organization. But, as far as non-technological programs are concerned, there is no clear evidence experienced by the employees with regard to business outcome of the company, but few of them were of the opinion that it helped them in developing strategic approach towards the business, through which they can understand the policies of the organization more efficiently.

\section{Conclusion}

NTPC is one of the leading energy conglomerates which are committed towards adoption of best practices in human resource development. The various stages followed by the energy giant under training and development process are; (i) training need assessment, (ii) designing the training program, (iii) implementation of the training program, and (iv) evaluation of training program. For training need assessment, the company makes organizational analysis wherein strategic issues the company foresee in near future are identified, which is followed by task analysis wherein the various skills to perform the tasks effectively and in an innovative manner are identified, and finally personal analysis wherein individual skills gaps are identified for performing a certain job. This helps the company to design the training and development activities which are highly focussed towards specific requirement. The company plans and implements the programs very meticulously by arranging the required resources from within and outside the organization. The Employee Development Centre (EDC) evaluates the programs for accomplishments of their objectives and makes the gap analysis. EDC is proactive in NTPC and comes up with innovative ideas to keep employees motivated by enriching and empowering them through various training and development activities which is evident from the overall perception of the employees towards the training and development practices adopted by NTPC.

\section{References}

1. Eneh S. I. \&Awara N. F. (2016), Strategic Human Resource Management Practices and Organizational Growth: A Theoretical Perspective, Global Journal Of Social Sciences, Vol 15, 27-37

2. Anil K. Sen Gupta: HRD in India, What is it? Journal of Decision vol 31 No;1 January-June 2004,pp 145176.

3. Appa Rao C and Gupta A.P: Training for Excellence at Rashtriyaispat Nigam Ltd, Indian Journal of Training and Development,XXXII;1-2 January 2004-2005

4. Benabon,C; Assessing the impact of Training and Development on the Bottom Line, National Productivity Review, vol,15pp91-96.

5. Virmani .B.R; Management Development in India,-Role of Management Education and Training Institutions in India, Indian Journal of Training and Development, XXXIV January -March 2004,pp 5-13.

6. NTPC Website

(http://www.ntpcindia.com/en/about-us/vision-and-mission)

(http://www.ntpcindia.com/en/about-us/ntpc-overview) 
7. Kaushik Manu (2010), People before PLF, Business Today, Cover Story, February 7. (https://www.businesstoday.in/magazine/cover-story/people-before-plf/story/5135.html)

\section{Annexure-I}

Training and Development Programs conducted during the period 2014-17

1. Strategic Vision- Core values of (BCOMIT) NTPC

2. Nurturing Strategic Thinking for Engineering Executives

3. Managing Human Capital-A Strategic Approach

4. Strategic Human Resource Management Practices

5. NTPC Core Values

6. Strategic Thinking for Competitive Advantage

7. NTPC Strategic Vision-Core Values actualization

8. Strategic HR for Managerial Effectiveness

9. HR for Line Managers

10. Leadership \&Technical Project Management

11. Personal Effectiveness" for Engineering

12. Managing Self' for Engineering

13. Conflict Management \& Negotiation Skills

14. Communication Skills for Engineering Executives 